\title{
Crescimento e desenvolvimento inicial da cultura da moringa (Moringa oleifera Lam.) submetida à fertilização orgânica
}

\section{Organic fertilization levels on the vegetative growth of moringa (Moringa oleifera Lam.)}

\author{
Tarso Moreno Alves de Souza ${ }^{1}$, Tassio Almeida Sousa ${ }^{2}$, Hélio Tavares de Oliveira Neto ${ }^{3}$, Lauter Silva Souto ${ }^{4}$, João de \\ Andrade Dutra Filho ${ }^{5}$, Aline Carla de Medeiros ${ }^{6}$
}

\begin{abstract}
Resumo: A moringa (Moringa oleifera Lam) é uma árvore nativa da Índia e de elevada importância principalmente pelo seu valor nutricional, medicinal e de purificação da água. Este trabalho teve como objetivo avaliar o efeito de níveis de fertilização orgânica no crescimento e desenvolvimento inicial de mudas de moringa nas condições semiáridas do Estado da Paraíba, Brasil. O experimento foi conduzido em condições de túnel plástico, localizado no Centro de Ciências e Tecnologia Agroalimentar, da Universidade Federal de Campina Grande, Campus de Pombal, UFCG. Utilizou-se o delineamento inteiramente casualizado, com os tratamentos compostos de sete níveis de fertilização orgânica $(0,0 ; 108,0 ; 216,0 ; 432,0$; 864,$0 ; 1728,0$ e 3456,0 g.vaso ${ }^{-1}$ ), com quatro repetições. Foram avaliados os seguintes parâmetros: i) altura das plantas (cm), ii) diâmetro do caule $(\mathrm{mm})$, iii) número de folhas, iv) fitomassa fresca das folhas, v) fiomassa seca da parte aérea (g), vi) fitomassa seca da raiz (g), vii) razão fitomassa seca da parte aérea/raiz $(\mathrm{g})$ e, viii) comprimento da raiz principal $(\mathrm{cm})$. A utilização dos níveis de fertilização orgânica influenciou significativamente o crescimento e desenvolvimento inicial das mudas de moringa. Com a elevação dos níveis de esterco adicionados ao substrato, observou-se o decréscimo das variáveis analisadas, tendo como melhor resultado o nível de 864,0 g.vaso ${ }^{-1}$ para a altura da planta e o nível de 432,0 g.vaso ${ }^{-1}$ para os demais parâmetros avaliados. O nível de 432,0 g.vaso ${ }^{-1}$ provocou os maiores acréscimos na massa seca da parte aérea e comprimento das raízes. Os níveis de esterco bovino de 108,0 g.vaso ${ }^{-1}$ e 432,0 g.vaso ${ }^{-1}$, promoveram um maior incremento para a razão entre a parte aérea/raiz e comprimento da raiz, respectivamente. Para produção de mudas de moringa de boa qualidade a aplicação de pequenas quantidades de esterco bovino é suficiente.
\end{abstract}

Palavras-chaves: Fertilizantes orgânicos, Semiárido, Silvicultura.

Abstract: Moringa (Moringa oleifera Lam) is a tree native of India and high importance especially for its nutritional value, medicinal and water purification. This work aimed to evaluate the effect of organic fertilization levels on growth and initial development of moringa seedlings in semi-arid conditions of the State of Paraiba, Brazil. The experiment was conducted in plastic tunnel conditions, located in the Centro de Ciências e tecnologia Agroalimentar da Universidade Federal de Campina Grande, Campus de Pombal, UFCG. We used a completely randomized design with the treatments composed of seven levels of organic fertilization $\left(0,0 ; 108,0 ; 216,0 ; 432,0 ; 864,0 ; 1728,0\right.$ e 3456,0 g.vaso $\left.^{-1}\right)$, with four repetitions. The following parameters were evaluated: i) plant height $(\mathrm{cm})$, ii) stem diameter $(\mathrm{mm})$, iii) number of leaves, iv) fresh weight of leaves, v) dry weight of shoots (g), vi) dry weight of the root $(\mathrm{g})$, vii) dry weight ratio of shoot / root $(\mathrm{g})$ and viii) main root length $(\mathrm{cm})$. The use of organic fertilization levels significantly influenced the growth and early development of moringa seedlings. With the rise of manure levels added to the substrate, there was the decrease of the variables analyzed, with a best result the level of 864.0 g.vaso ${ }^{-1}$ for plant height and the level of 432.0 g.vaso $^{-1}$ for the other parameters. The level of 432.0 g.vaso ${ }^{-1}$ caused the $^{-1}$ greatest increases in dry weight of shoot and root length. The levels of bovine manure 108.0 g.vaso ${ }^{-1}$ and 432.0 g.vaso ${ }^{-1}$, promoted a greater increase for the ratio of root / shoot and root length, respectively. To produce good quality moringa seedlings the application of small amounts of bovine manure is sufficient.

Key words: Vigna unguiculata, semi-arid, emergency, water availability.

\footnotetext{
*Autor para correspondência

Recebido para publicação em 20/11/2015; aprovado em 23/12/2015

${ }^{1}$ Graduando em Agronomia, UFCG, Pombal-PB. Fone: (83) 3431-4000, tarsobh@ hotmail.com

${ }^{2}$ Graduando em Agronomia, UFCG, Pombal-PB.. Fone: (83) 3431-4000, tassiobuzu@ hotmail.com.br

${ }^{3}$ Graduando em Agronomia, UFCG, Pombal-PB. Fone: (83) 3431-4000, helio_tavares@ hotmail.com

${ }^{4}$ Eng. Agr. D.Sc., Professor da Unidade Acadêmica de Ciências Agrárias, UFCG, Pombal-PB. Fone: (83) 3431-4000 filho-dutra@ig.com.br

${ }^{5}$ Biólogo D.Sc., Professor da Unidade Acadêmica de Ciências Agrárias, UFCG, Pombal-PB. Fone: (83) 3431-4000 lauter@ccta.ufcg.edu.br

${ }^{6}$ Eng. Agr. Doutoranda em Engenharia de Processos pela UFCG - Campina Grande - PB alinecarla.edu@ gmail.com
} 


\section{INTRODUÇÃO}

A moringa (Moringa oleifera Lam), conhecida popularmente por lírio branco, quiabo-de-quina, acáciabranca, árvore-rabanete-de-cavalo e cedro, é uma hortaliça arbórea de origem indiana que chega até 8 metros de altura (PEREIRA et. al., 2014).

É considerada uma espécie arbórea exótica que se adaptou satisfatoriamente às condições edafoclimáticas do semiárido do Nordeste brasileiro. A planta possui uma variedade imensa de aplicações, sendo chamada por muitos de planta multiuso, sendo também, uma esperança para o combate a fome no mundo devido sua composição rica em vitaminas e sais minerais (JESUS et. al., 2013).

As sementes apresentam propriedades floculantes ou coagulantes, sendo utilizadas em diversos países como um método natural, eficiente e econômico de purificação de água (GASSENSCHMIDT et al.,1995). As folhas podem ser utilizadas na alimentação humana por apresentarem grandes quantidades de nutrientes, proteínas, teores de betacaroteno e vitamina $\mathrm{C}$ quando comparadas a outros alimentos e um alto potencial para a melinoponicultura da região.

A adubação na produção de mudas arbóreas vem sendo bastante pesquisado, e, na maioria dos casos, os resultados demonstram a importância desta prática na obtenção de mudas mais vigorosas e com melhor estande após plantio no campo (PEREIRA et. al., 2014).

A aplicação frequente de adubação orgânica em espécies arbóreas é de fundamental importância por influenciar nas características físicas, químicas e biológicas do solo, favorecendo assim, melhores condições para produção de mudas de boa qualidade na fase de viveiro (GUIMARÃES, et. al., 2006).

É fato conhecido que todos os sistemas produtivos, tanto agrícolas, quanto pecuários, dão origem a vários tipos de resíduos orgânicos, os quais corretamente manejados e utilizados revertem-se em fornecedores de nutrientes para a produção de alimentos e melhoradores das condições físicas, químicas e biológicas do solo. Com o aumento dos custos da adubação mineral, o agricultor passou a ter uma nova visão sobre a adubação orgânica.

Visto a importância da espécie para a região, o presente estudo teve como objetivo avaliar o efeito da aplicação de níveis de fertilização orgânica no crescimento e desenvolvimento inicial de mudas de moringa (Moringa oleifera Lam.) em amostras de Luvissolo Crômico no semiárido do Estado da Paraíba, Brasil..

\section{MATERIAL E MÉTODOS}

O experimento foi conduzido no período de junho de 2015, em condições de túnel plástico, localizado no Centro de Ciências e Tecnologia Agroalimentar, da Universidade Federal de Campina Grande, Campus de Pombal, UFCG. A localização geográfica está definida pelas coordenadas: $06^{\circ} 46^{\prime} 13^{\prime}$ 'S e $37^{\circ} 48^{\prime} 06^{\prime \prime} \mathrm{W}$, com altitude aproximada de 242 m. O clima segundo classificação de Köppen é no tipo Bsh (semiárido) quente e seco, com pluviosidade média anual inferior a $1000 \mathrm{~mm} /$ ano com chuvas irregulares e médias anuais térmicas superiores a $25^{\circ} \mathrm{C}$.

$\mathrm{O}$ delineamento estatístico adotado foi o inteiramente casualizado, com os tratamentos constituídos por sete níveis de esterco bovino $(0,0 ; 108,0 ; 216,0 ; 432,0 ; 864,0 ; 1728,0$ e 3456 g.vaso $^{-1}$ ), com quatro repetições, totalizando 28 unidades experimentais. $\mathrm{O}$ ensaio foi realizado em recipientes com capacidade de $20 \mathrm{dm}^{3}$, em solo classificado como Luvissolo Crômico (EMBRAPA, 2013), apresentando as seguintes características químicas na profundidade de 0$20 \mathrm{~cm}: \mathrm{pH}_{\mathrm{H} 20}=6,4 ; \mathrm{P}=36 \mathrm{mg} \cdot \mathrm{dm}^{-3} ; \mathrm{k}=0,16 \mathrm{cmol}_{\mathrm{c}} \cdot \mathrm{dm}^{-3} ; \mathrm{Ca}=$ $3,4 \mathrm{cmol}_{\mathrm{c}} \cdot \mathrm{dm}^{-3} ; \mathrm{Mg}=2,3 \mathrm{cmol}_{\mathrm{c}} \cdot \mathrm{dm}^{-3} ; \mathrm{Al}=0,3 \mathrm{cmol}_{\mathrm{c}} \cdot \mathrm{dm}^{-3} \mathrm{e}$ $\mathrm{CTC}=9,0 \mathrm{cmol}_{\mathrm{c}} \cdot \mathrm{dm}^{-3}$.

A semeadura foi realizada com cinco sementes por unidade experimental à profundidade de $2 \mathrm{~cm}$. As irrigações foram realizadas deixando-se o solo com uma capacidade de campo aproximada de $60 \%$. Para se atingir o nível de água desejado, foi estabelecida a capacidade de campo do solo colocando-o em um vaso $\left(20 \mathrm{dm}^{3}\right)$ e saturando-o com irrigação em uma lâmina previamente estabelecida. Após 24 h e verificado o fim do cessamento da drenagem, verificou-se a quantidade de água drenada e a quantificou subtraindo a quantidade irrigada pela quantidade drenada. Estipulando assim, a partir da quantidade de água retida no solo, a água disponível do solo em questão.

As irrigações foram realizadas através de pesagens diárias em todas as parcelas com o auxílio de uma balança eletrônica, de modo que o volume total em peso (vaso + solo + água) era reposto a partir da quantidade de água que era perdida (evapotranspiração). As irrigações foram realizadas em turno de rega fixo, diariamente sempre no intervalo das 16 às 17: $00 \mathrm{~h}$, com o auxílio de um regador e distribuída de forma lenta e em pequenas quantidades, para que ocorresse melhor uniformidade da área irrigada.

Foram avaliados no presente estudo as seguintes variáveis: i) altura das plantas (cm), ii) diâmetro do caule $(\mathrm{mm})$, iii) número de folhas, iv) fitomassa freca das folhas, v) fiomassa seca da parte aérea $(\mathrm{g})$, vi) fitomassa seca da raiz (g), vii) razão fitomassa seca da parte aérea/raiz (g) e, viii) comprimento da raiz principal $(\mathrm{cm})$.

As avaliações foram realizadas aos quinze dias após a emergência (DAE). As plantas coletadas foram separadas em partes (raiz, caule e folhas) para a obtenção da massa seca, sendo acondicionadas em sacos de papel identificados, e em seguida foram postas em estufa com circulação forçada de ar a $60^{\circ} \mathrm{C}$ durante 36 horas. Após a secagem, em balança analítica com precisão de $0,001 \mathrm{~g}$ foi determinado à massa seca da parte aérea e do sistema radicular.

Os dados obtidos foram avaliados estatisticamente, através da análise de variância. Foram testados os modelos linear e quadrático, sendo selecionado para expressar o comportamento de cada variável o modelo que apresentou significância a $5 \%$ de probabilidade e o maior coeficiente de correlação para os dados obtidos. Foi utilizado o programa SISVAR para realização das análises estatísticas (FERREIRA, 2003).

\section{RESULTADOS E DISCUSSÃO}

Os resultados para a altura de planta e diâmetro de caule foram afetados pelos níveis de esterco bovino adicionados nos diferentes tratamentos (Figura 1a e 1b). A altura de plantas foi crescente com o aumento dos níveis de esterco adicionados ao solo (Figura 1a), com os maiores valores obtidos no tratamento com 1728,0 g.vaso ${ }^{-1}$ de esterco bovino, ocorrendo uma redução drástica em altura das plantas 
a partir deste valor, sendo para as condições do presente estudo a quantidade de fertilizante orgânico suficiente para que as plantas de moringa expressassem o máximo de crescimento. Observa-se que a relação entre altura de planta e níveis de esterco bovino, o comportamento foi quadrático. A relação de dependência da altura de planta em função da quantidade de fertilizante orgânico aplicada pode ser verificada no coeficiente de determinação $\left(R^{2}=0,7092\right)$.

Com relação ao diâmetro de colmo (Figura 1a), houve uma redução com a elevação dos níveis de esterco bovino adicionados. $\mathrm{O}$ menor diâmetro foi obtido para as doses de 1728,0 e 3456,0 g.vaso ${ }^{-1}$ de esterco, o que vem a confirmar o mecanismo de adaptação desta espécie exótica às condições semiáridas do nordeste brasileiro. Resultados semelhantes foram obtidos por Oliveira Júnior et al. (2009), que estudando o efeito de fontes de fertilizantes orgânicos na cultura da moringa, em Patos-PB, observaram maiores diâmetros de caule quando o esterco bovino foi aplicado como fonte de fertilização da cultura. $\mathrm{O}$ efeito quadrático e o alto coeficiente de determinação $\left(\mathrm{R}^{2}=0,8141\right)$ da adubação orgânica indicam que doses maiores de esterco levariam a decréscimos no diâmetro de colmo até certo limite, observando-se um decréscimo no aproveitamento dos nutrientes aplicados através da fertilização orgânica.

Nas figuras $2 \mathrm{a}$ e $2 \mathrm{~b}$ são apresentados os valores para número de folhas e fitomassa fresca da parte aérea. O número de folhas foi decrescente com o aumento das doses de esterco bovino ao solo (Figura 2a). Entretanto, a testemunha (sem aplicação) proporcionou o maior número de folhas por planta, quando comparado à dose de 3456,0 g.vaso ${ }^{-1}$ de esterco bovino. A análise de regressão do número de folha em função das doses de esterco, revelou ajuste significativo. $\mathrm{O}$ coeficiente de determinação $\left(\mathrm{R}^{2}=0,7478\right)$ indica que uma fração significativa da variação no número de folhas por planta pode ser explicada pelas diferentes doses de esterco bovino aplicadas.

Para a produção de fitomassa fresca da parte aérea observa-se um efeito significativo e ajuste quadrático das diferentes doses de esterco bovino adicionadas ao solo (Figura 2b). A menor produção de fitomassa foi apresentada no tratamento com aplicação de 3456,0 g.vaso ${ }^{-1}$, quando comparado ao tratamento com aplicação de 432,0 g.vaso ${ }^{-1}$, que apresentaram valores de 0,20 e 0,63 g.planta ${ }^{-1}$, respectivamente.

Figura 1. Valores médios de altura de plantas (a) e diâmetro de caule (b) aos 15 DAE, em função de variações nos níveis de fertilização orgânica. Pombal, PB, 2015

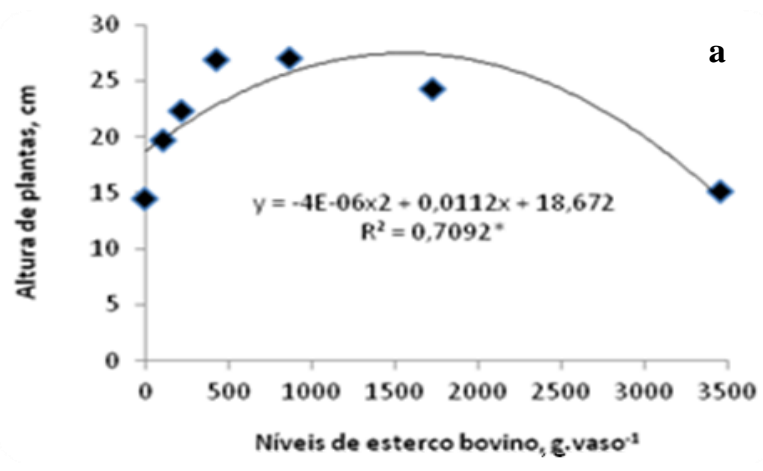

O aumento nos níveis de fertilização orgânica adicionados ao solo proporcionaram um aumento significativo na produção de massa seca da parte aérea e de raiz (Figura 3a e 3b), com valores máximos observados nas doses de 432,0 e 864,0 g.vaso ${ }^{-1}$, respectivamente. A partir destes valores, observa-se um decréscimo da FSPA e FSR em função dos níveis de esterco adicionados aos tratamentos.

Verificou-se que os níveis de esterco bovino de 432,0, 216,0 e 864,0 g.vaso ${ }^{-1}$ apresentaram ganhos de 57,0, 25,0 e $12,0 \%$ de fitomassa seca da parte aérea,

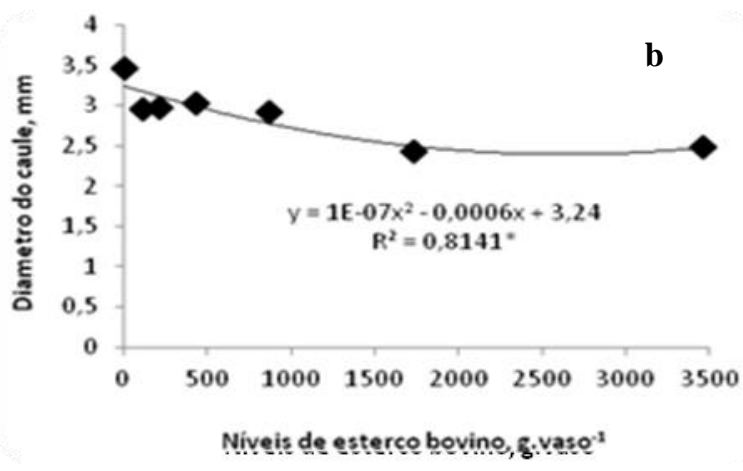

respectivamente, quando comparados à testemunha (sem aplicação). Isto evidencia que a aplicação de 432,0 g.vaso ${ }^{-1}$ de esterco bovino promove as melhores respostas da cultura devido às condições mais favoráveis ao crescimento inicial das mudas e melhor fornecimento de nutrientes durante o período avaliado. Artur et al. (2007), observou um comportamento semelhante em função da adição de esterco bovino e calagem na formação de mudas de guanandi, onde o aumento das doses de esterco proporcionou um decréscimo nos índices de FSPA.

Figura 2. Número de folhas (a) e fitomassa fresca (b) aos 15 DAE, em função de variações nos níveis de esterco bovino. Pombal, PB, 2015.
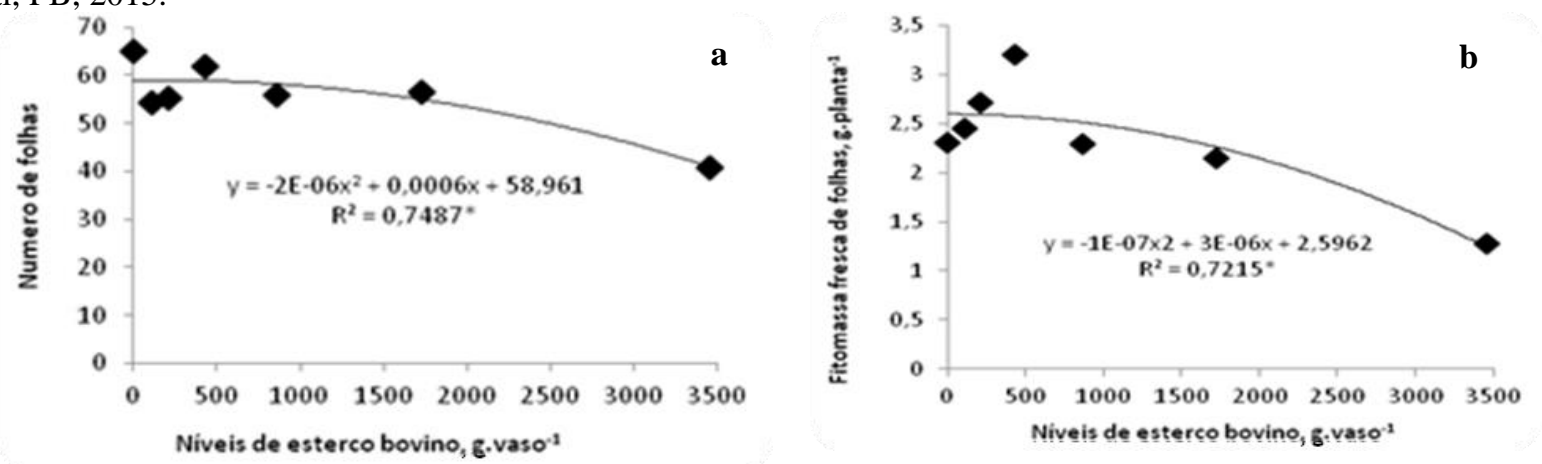
Figura 3 - Resultados obtidos para as variáveis de fitomassa seca da parte aérea (a) e fitomassa seca da raiz (b) de Moringa oleifera Lam., em função de níveis de fertilização orgânica. Pombal, PB, 2015.

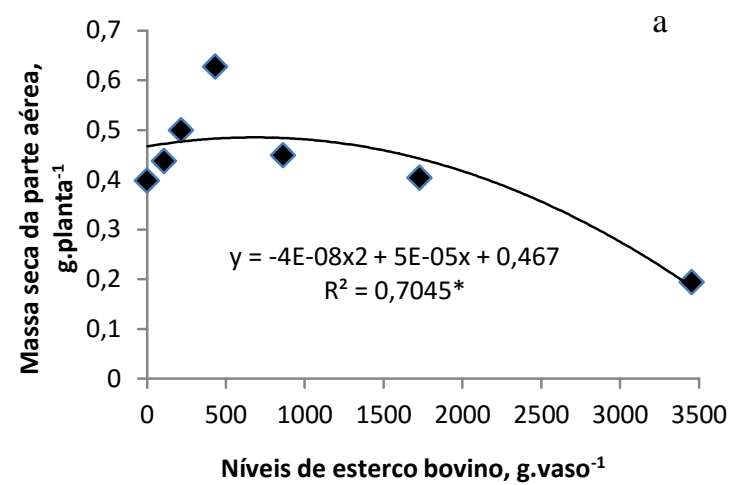

Os valores médios da razão parte aérea/raiz e comprimento da raiz submetidos aos diferentes níveis de fertilização orgânica encontram-se nas Figuras $2 \mathrm{a}$ e 2b. Para a razão entre a parte aérea/raiz, foi possível observar que os níveis de esterco bovino de 108,0 e 216,0 g.vaso ${ }^{-1}$, promoveram um maior incremento para esta razão, sendo assim são os mais indicados para suprir necessidade da planta, tendo em vista que este parâmetro é de grande importância com relação ao desenvolvimento de mudas em condições de campo. Caldeira, et al. (2008), avaliando a influência de composto orgânico na produção de mudas de aroeiravermelha, observou que o substrato contendo $40 \%$ de composto orgânico, apresentou melhores resultados com relação a razão da parte aérea/raiz, quando comparado aos demais tratamentos. Os mesmos autores ainda afirmam que é importante analisar esta relação em plantas em condições de

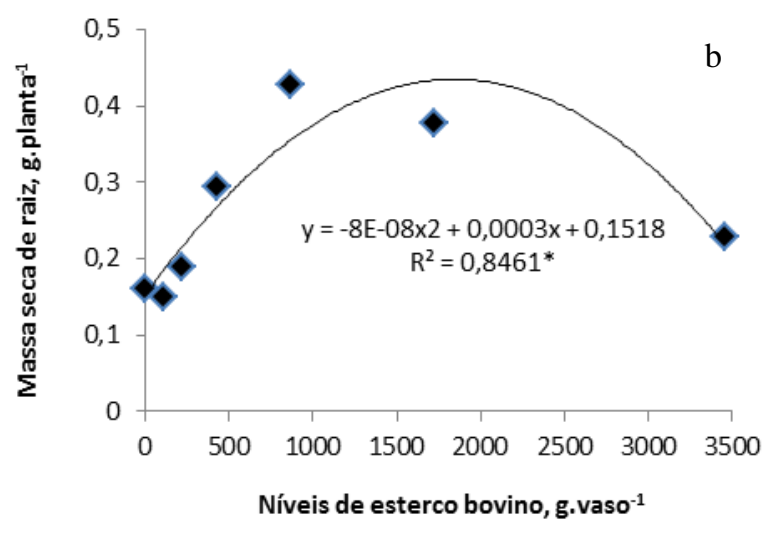

campo, uma vez que a parte aérea não deve ser muito superior a raiz, caso contrário, pode ocorrer problemas com relação à absorção de água a ser transportada para a parte aérea.

Com relação ao comprimento da raiz, observou-se que os níveis de 216,0, 432,0, 864,0 g.vaso $^{-1}$ de esterco bovino, proporcionaram um maior incremento, onde a dose de 432 g.vaso $^{-1}$ foi superior aos demais níveis avaliados. Os resultados se assemelham aos encontrados por Silva, et al, (2008), observou no crescimento de mudas de craibeira que a adição de 5\% de esterco bovino, proporcionou um maior aumento no comprimento da raiz. Alves (2012), avaliando a influencia de diferentes substratos em mudas de faia (Emmotum nitens Benth), observou que ao adicionar matéria orgânica no substrato o comprimento da raiz os resultados foram inferiores aos tratamentos que não receberam a adição de matéria orgânica no substrato.

Figura 4 - Resultados obtidos para as variáveis razão parte aérea/raiz (a) e comprimento de raiz (b) de Moringa oleifera Lam., em função de níveis de fertilização orgânica. Pombal, PB, 2015.

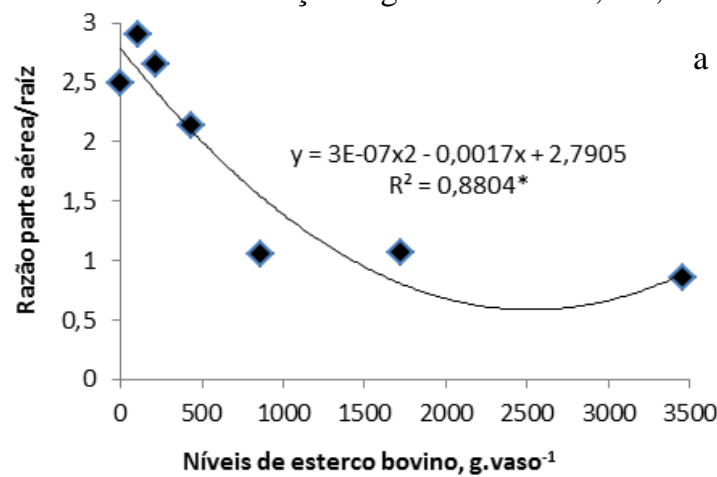

\section{CONCLUSÕES}

A fertilização orgânica com a aplicação de 416,0 g.vaso 1 foi suficiente para promover um crescimento e desenvolvimento mais adequado das mudas de Moringa oleífera Lam.

A adição de 3456,0 g.vaso $^{-1}$ de esterco bovino implicou no menor crescimento e desenvolvimento inicial de mudas de moringa.

Pode-se recomendar o esterco bovino para produção de mudas como fonte de nutrientes e condicionador do solo.

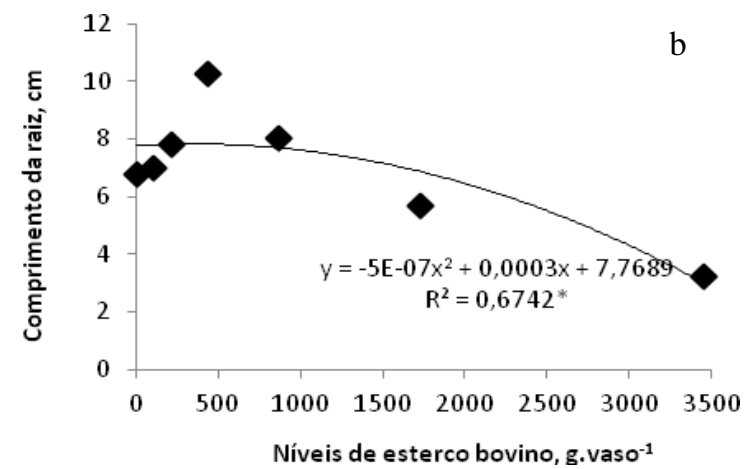

REFERÊNCIAS BIBLIOGRÁFICAS

ALVES, M. V. P. Produção de mudas de Emmotum nitens (Benth.) Miers (Icacinaceae) em diferentes composições de substratos. Revista Verde de Agroecologia e Desenvolvimento Sustentável, v. 7, n. 2, p 225-235, 2012.

ARTUR, A. G.; CRUZ, M. C. P.; FERREIRA, M. E.; BARRETTO, V. C. M.; YAGI, R. Esterco bovino e calagem para formação de mudas de guanandi. Pesquisa Agropecuária Brasileira, v. 42, n. 6, p. 843 - 850, 2007. 
BENEDITO, C. P.; RIBEIRO, M. C. C.; TORRES, S. B. Salinidade na germinação da semente e no desenvolvimento das plântulas de moringa (Moringa oleifera Lam.). Revista Ciência Agronômica, v. 39, n. 3, p. 463-467.

CALDEIRA, M. V. W.; ROSA, G. N.; FENILLI, T. A. B.; HARBS, R. M. P. Composto orgânico na produção de mudas de aroeira-vermelha. Scientia Agraria, v. 9, n. 1, p. 27-33, 2008.

EMBRAPA. Centro Nacional de Pesquisa de Solos (Rio de Janeiro-RJ). Sistema Brasileiro de Classificação de Solos. Rio de Janeiro: EMBRAPA Solos, 2013. 431 p.

FERREIRA, D. F. Programa de análises estatísticas e planejamento de experimentos - SISVAR 5.0 (Build 67). Lavras: DEX/UFLA, 2003.

GASSENSCHMIDT, U.; JANKY， K. D; TAUSC, B.; NIEBERGAL, H. Insolation and characterization of a flocculating protein from Moringa oleífera Lam. Biochemistry Biophyscial Acta, v.13, p.477-481, 1995.

GOMES, J. M. Parâmetros morfológicos na avaliação da qualidade de mudas de Eucalyptus grandis, produzidas em diferentes tamanhos de tubetes e de drenagem de $\mathrm{N}$ P-K. 2001. 126 f. Tese (Doutorado em Ciências
Florestais) - Universidade Federal de Viçosa, 126f, 2001.

GUIMARÃES, M. M. B. et al. Produção de muda de mamoneira em substrato contendo diferentes resíduos orgânicos e fertilizante mineral. Anais... In: Congresso Brasileiro de Mamona, 2, 2006.

JESUS, A. R. et al. Cultivo da Moringa Oleífera. Instituto Evaldo Lodi - IEL/BA. 2013. 23p. (Dossiê técnico).

MALAVOLTA, E. ABC da adubação. 5. ed. São Paulo: Agronômica Ceres, 1989. 292 p.

OLIVEIRA JUNIOR, S. et al. Adubação com diferentes estercos no cultivo de moringa (Moringa oleifera LAM.) Revista Verde de Agroecologia e Desenvolvimento Sustentável, v.4, n.1, p.125 - 134 janeiro/março de 2009.

PEREIRA, K. T. O. et al. Efeito de níveis de fertilizantes na produção de mudas de moringa. In: Inovagri International Meeting, 2., 2014, Fortaleza-Ceara. Anais... Fortaleza: INOVAGRI, 2014.

SILVA, G. H.; SANTOS, R. V.; GOMES, A. D. V. Crescimento de mudas de craibeira em substrato de coproduto sob fertilização química e orgânica. Revista Verde de Agroecologia e Desenvolvimento Sustentável, v. 9 , n. 5, p. $78-83,2014$. 